\title{
Using a DEA Management Tool through a Nonparametric Approach: An EXAMination of URban-RuRAl EFFECTS ON THAi SCHOOl EFFICIENCY
}

\author{
SANGCHAN KANTABUTRA \\ Mae Fah Luang University
}

\begin{abstract}
This paper examines urban-rural effects on public upper-secondary school efficiency in northern Thailand. In the study, efficiency was measured by a nonparametric technique, data envelopment analysis (DEA). Urban-rural effects were examined through a Mann-Whitney nonparametric statistical test. Results indicate that urban schools appear to have access to and practice different production technologies than rural schools, and rural institutions appear to operate less efficiently than their urban counterparts. In addition, a sensitivity analysis, conducted to ascertain the robustness of the analytical framework, revealed the stability of urban-rural effects on school efficiency. Policy to improve school eff iciency should thus take varying geographical area differences into account, viewing rural and urban schools as different from one another. Moreover, policymakers might consider shifting existing resources from urban schools to rural schools, provided that the increase in overall rural efficiency would be greater than the decrease, if any, in the city. Future research directions are discussed.
\end{abstract}

Kantabutra, S. (2009). Using a DEA Management Tool through a Nonparametric Approach: An Examination of Urban-Rural Effects on Thai School Efficiency. International Journal of Education Policy and Leadership 4(2). Retrieved [DATE] from http://www.ijepl.org.

\section{Introduction}

With the scope of unprecedented and unstoppable change in this globalization age, governments in the Asia-Pacific region are finding it increasingly difficult to put their educational policies into practice (Cheng \& Townsend, 2000; Hallinger, 1998). Although education is a major government expenditure for the region's countries, the capacity of their educational systems to meet the new demands of the global age is still in question (Booth, 1999). Thailand, one of the relatively fast-growing economies of Southeast Asia, has been providing the largest share of total public expenditure to education since 1991. Even after the 1997 economic crisis began, the government provided 25 percent of its total expenditure, or 4.3 percent of the Gross Domestic Product (GDP), for education, which was a greater portion than ever before, demonstrating commitment to education for the nation's recovery and development (Office of Education Council [OEC], 2004).

In recent years, although Thai education has achieved gains in many areas (e.g., higher literacy and enrollment rates), the urban-rural differentials that have affected educational services still exist throughout all regions in the country (Office of the National Education Commission [ONEC], 2001). As indicated in a 1996 World Bank poverty report, the increase in inequality between urban and rural areas was largely due to the skewed distribution of formal sector jobs, the poverty incidence rate, wage differentials, and the limited access of the poor to secondary and vocational education. Moreover, income inequality in the two areas also affected household education expenditure (World Bank, 1996). In addition, the average growth of urban household income (20 percent during 1988-1992) was almost twice as fast as the growth in rural areas, exacerbating the large income differential that already existed (World Bank, 1996). Since equity of access to quality education for urban and rural schools, particularly access for provincial and low-income populations to educational services and infrastructure, has affected Thai schools (Atagi, 2002; OEC, 2004), improvements in these areas can improve school efficiency and alleviate urban-rural differentials for the country (National Economic and Social Development [NESDB], 2002). 
The purpose of this study was to estimate school efficiency, examine urban-rural effects on school efficiency, and ascertain the robustness of urban-rural effects on efficiency. The study employed a nonparametric technique, data envelopment analysis (DEA), to assess efficiency of public general upper-secondary schools in northern Thailand. It is commonly agreed that policymakers consider school efficiency as a critical performance indicator (Bradley, Johnes, \& Millington, 2001; Mante \& O'Brien, 2002), without claiming that it exhaustively explains overall school performance. DEA has been recognized as a useful management tool (Manandhar \& Tang, 2002; Watcharasriroj \& Tang, 2004), because it compares a given unit to the best-performing units in its peer group. The results obtained from such analysis can identify relatively efficient and inefficient organizations and allow policymakers to develop performance-based policies to help inefficient ones improve their performance.

Being in an urban or a rural location can affect school efficiency because of differences in patterns of economics, society, and environment related to school quality (Gilbert \& Gugler, 1992; Pritchard, 2003). Although the DEA technique has also been used to evaluate urban-rural effects on school efficiency internationally during the past decade-for example, in schools in Cyprus (Soteriou, Karahanna, Papanastasiou, \& Diakourakis, 1998), schools in Spain (Mancebón \& Bandrés, 1999), and schools in Finland (Kirjavainen \& Loikkanen, 1998)_very few studies have dealt with school efficiency and urban-rural effects in Thailand. The novel methodological contribution of this study is a statistical foundation of output efficiency measurements along with a second-stage analysis of urban-rural effects on efficiency and the robustness test.

The paper begins with an overview of theoretical and empirical studies of urban-rural effects on school efficiency. It then describes the analytical framework, data and results, and the test of robustness of urban-rural effects on school efficiency. The paper ends by providing conclusions, recommendations, and suggestions for future research directions.

\section{Urban-Rural Effects on School Efficiency}

The basic meaning of the terms "urban" and "rural" is fairly clear, the former referring to the city and the latter to the countryside or areas outside the city (Morris, Bailey, Turner, \& Bateman, 2001), but the actual patterns of settlement between the two are different. Hugo et al. (1997) classified the urban and rural differentials in terms of economic activities, occupations, education level, access to infrastructure, population, politics, nationality, and migration, and concluded that urban areas gain the advantage in all dimensions. That is, urban areas have higher levels of economic activities, especially in manufacturing, construction, and services; greater access to infrastructure; and higher educational levels, whereas rural areas function mainly at a basic level of economic activity, mostly in agriculture and farming, with less access to infrastructure and lower educational levels. Further, the economic decline in agriculture create a ripple effect on nonfarm economies in rural communities, resulting in declining school enrollments and the loss of more rural graduates to urban areas, where work is more plentiful (Lasley, Leistritz, Lobao, \& Meyer, 1995). These differences are important factors in the rural migrants' decision to move to urban areas in search of better job opportunities and better school quality and public facilities (Gilbert \& Gugler, 1992).

Effects of the urban-rural differentials can be further explained by differentials in households' socioeconomic status (SES) as related to academic achievement. Socioeconomic and family status, mostly measured by family income or education level, is regarded as one of most significant factors affecting student achievement (Hanushek, 1986; Rutter, Maughan, Mortimore, \& Ouston, 1979). Urban dwellers, on average, have higher levels of occupation, income, and education, and enjoy better-quality public services, resulting in a higher socioeconomic status. Noting that low socioeconomic status is associated with conditions that make learning more difficult (Hochschild, 2003; Mante \& O'Brien, 2002), urban schools, which tend to have students with higher socioeconomic status than their rural counterparts, often have more advantages in operations when compared to rural schools.

In addition to the lower socioeconomic status of their pupils, rural schools have funding drawbacks. The central government in Thailand is the main source for allocating funds to public schools, and funding occurs without reference to differentials in socioeconomic levels between areas or an area's capacity to raise revenue. In political debates over school funding, rural schools are often overlooked because they are small, sparsely populated, and widely dispersed (Pritchard, 2003). Funding is frequently tied to enrollment, and rural schools usually serve fewer students and experience declining enrollment, generating severe financial distress. These financial constraints set the stage for a vicious circle of staff and program reductions, neglected facility maintenance and 
improvement, lower morale, decreased educational opportunities and experiences, curtailment of professional growth activities, and eventual school closure (Jimerson, 2006). Rural schools' facilities tend to be older than their urban counterparts' facilities; years of inadequate funding have resulted in more than half having inadequate structural or mechanical features (McColl $\&$ Malhoit, 2004). Rural schools thus operate with less revenue, while many costs are fixed or increasing.

Nonetheless, several rural community characteristics benefit rural students. Rural communities often see their school as the glue of the area, providing cohesion and identity to a dispersed citizenry. Rural schools usually serve close-knit communities in which the school plays an important role and can be a vibrant gathering center and symbol of pride (Miller, 1995; Pritchard, 2003). Rural schools thus benefit from closer ties between school and community. Rural schools also provide local economic benefits, since closing rural schools can strangle the fragile economy of rural communities (Bingler et al., 2002).

Studies of empirical evidence of urban-rural effects on school efficiency yield mixed results. Knight and Li (1996) found that urban schools were more efficient than rural schools in China due to a substantial positive predictor of increased educational attainment by students ages 16 years of age and older. Cooksey, Balze, and Burian (1998) revealed that urban schools were more efficient than rural ones in Tanzania in terms of school access and performance. Adewuyi (2002) reported that rural schools were less efficient than urban ones in Nigeria. Saitis and Saiti (2004) investigated the management and functionality of public urban and rural school libraries in Greece and found that urban school libraries were more efficient than rural ones. Several studies have used DEA techniques to measure the influence of urbanrural effects on school efficiency. Mancebón and Bandrés (1999) evaluated secondary schools efficiency in Spain and found that urban schools were more efficient than rural schools. However, Soteriou et al. (1998) revealed that there were no efficiency differences between urban and rural secondary schools in Cyprus.

\section{The Analytical Framework}

Examining the robustness of urban-rural effects on school efficiency would entail (1) measuring school efficiency, (2) investigating the urban-rural effects on efficiency, and (3) examining the robustness of urban-rural effects on efficiency.
This study used data envelopment analysis (DEA), a nonparametric technique initially introduced by Charnes et al. (1978), to assess school efficiency by viewing schools as productive units using multiple inputs to generate multiple outputs.

DEA has been used and cited internationally as an important approach (e.g., Bradley et al., 2001; Kirjavainen \& Loikkanen, 1998; Mancebón \& Bandrés, 1999; Mante \& O’Brien, 2002; Soteriou et al., 1998) and was proposed to measure school efficiency in Thailand (e.g., Kantabutra \& Kantabutra, 2004, 2005, 2006; Kantabutra, 2008).

DEA is extensively used as a popular educational management tool due to its several unique advantages over traditional techniques, such as ratio and regression analysis (Engert, 1996; Hanushek, 1986; de Lancer, 2000): (1) DEA can handle multiple inputs and outputs on a simultaneous basis; (2) DEA does not require parametric specification in a mathematical form; (3) DEA does not assume behavioral activities such as cost minimizing or profit seeking, which is especially relevant to public schools because they are nonprofit organizations; (4) inputs and outputs that are contributing to inefficiency are identified, and administrators can decide whether a reallocation of resources is necessary or feasible; and (5) managerial strategies for improvement of inefficient decision-making units can be determined.

With the use of the DEA technique to assess school efficiency, schools are considered as production or decision-making units (DMUs). Thus, the production function of a school can be explained by a DEA input-output model (Figure 1) as proposed by Anderson, Sweeney, and Williams (1997). According to this model, a production process is a mechanism in which educational resources (e.g., controllable and uncontrollable inputs) are used to produce outputs or outcomes. This framework can show that inefficiency of school units can be caused by poor educational production mechanisms, uncontrollable environmental factors over the production process, or both.

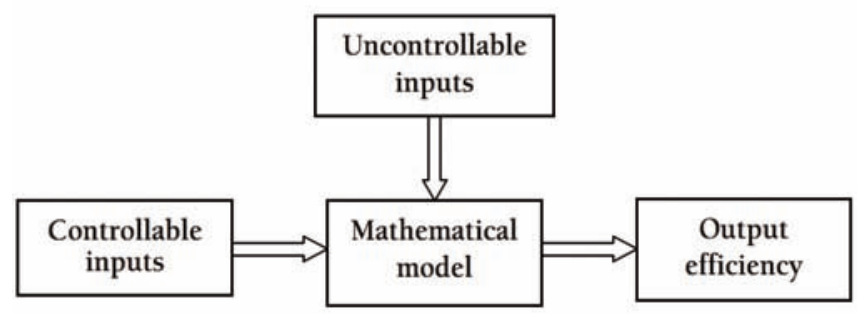

Figure 1. Input-Output Model 
Moreover, a model of a school production function might have, for example, three inputs $\left(x_{1}, x_{2}, x_{3}\right)$ and three outputs $\left(y_{1}, y_{2}, y_{3}\right)$. For this study, schools in the sample were divided into urban or rural (Figure 2). Each DMU's efficiency was measured twice: (1) relative to its own separate frontier (Separate Efficiency) or, in other words, measured within its own group, and (2) relative to the pooled frontier (Pooled Efficiency), or measured within the pooled sample.

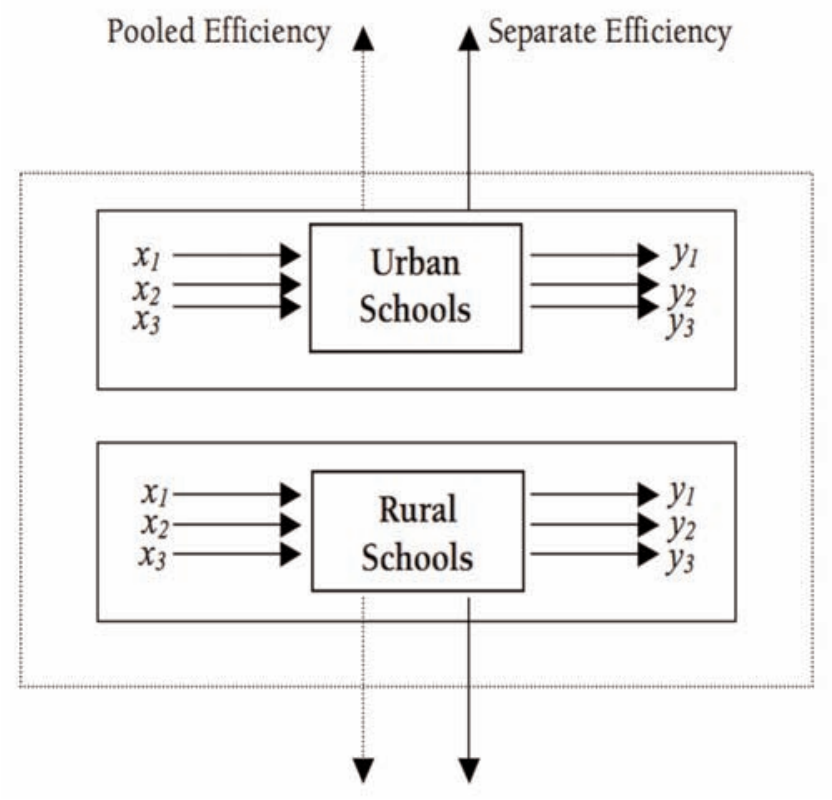

Figure 2. Measure of School Efficiency

The output maximization DEA model measures the extent to which outputs can be expanded for a given set of inputs, whereas the input minimization DEA model measures how much inputs can be proportionally further reduced for a given level of output (Coelli, Rao, \& Battese, 1998). In the context of public schools, Mancebón and Bandrés (1999) noted that an output maximization DEA model was a more appropriate behavioral assumption to take than an input minimization one, since school principals should be oriented toward obtaining the best results on the basis of the resources available to them rather than minimizing resources over which they exercise no control (a philosophy that is implicit in the output orientation version). A number of studies-including studies by Mancebón and Bandrés (1999), Bradley et al. (2001), Mante and O'Brien (2002), and Primont and Domazlicky (2006) —used the output-oriented approach for assessing school efficiency.

For calculating efficiency, the DEA technique can be carried out by solving an output-oriented linear equa- tion, incorporating the assumption of constant returns to scale, such as the following equation [(Equation (1)].

$$
\begin{array}{cc}
\text { Maximize: } \mathrm{Z}_{0}= & \left.\phi_{0}+\varepsilon \mid \sum_{i=1}^{-} s_{i}^{-}+\sum_{r=1}^{\infty} s_{r}^{+}\right] \\
\text {Subject to: } & \sum_{j=1}^{n} y_{r j} \lambda_{j}-s_{r}^{+}-y_{r 0} \phi_{0}=0, \\
& \sum_{j=1}^{n} x_{i j} \lambda_{j}+s_{i}^{-}-x_{i 0}=0, \\
& s_{i}^{-} \geq 0 ; s_{r}^{+} \geq 0 ; \lambda_{j} \geq 0 \\
\text { Equation } 1 . & i=1, \ldots, m ;
\end{array}
$$

where $x_{i j}$ and $y_{r j}$ represent the observed values of the ith input and the rth output for school $j(j=1, \ldots, n) ; \lambda_{j}$ is the input and output weights of other schools; $s_{i}{ }^{-}$and $s_{i}{ }^{+}$ are the slacks; $\phi_{0}$ represents the efficiency of the school being evaluated; and $\varepsilon$, a small positive constant, guarantees that inputs and outputs are positive and that the slacks do not influence the target function $\mathrm{Z}_{0}$.

For assessing all schools in the sample, Equation (1) is solved $n$ times, giving $n$ sets of $\lambda_{j}$, one set for each school, to determine each school's relative efficiency. In an output-oriented DEA model, technical efficiency is measured by the reciprocal of the output distance function (Coelli et al., 1998; Primont \& Domazlicky, 2006). The reciprocal of the direct output function gives the proportion by which all outputs can be expanded, given the inputs. This output-oriented DEA model implies that the efficiency score $(\phi)$ will be equal to or higher than 1 . An efficiency score $(\phi)$ of 1 , together with nil values for all the slacks, indicates efficiency-that is, that the school being evaluated has attained the maximum possible production on the basis of the limited resources available to it and the conditions under which it operates. A score higher than 1 indicates that the school being evaluated could increase its production by the proportion $(\phi-1)$ without changing its current resources.

The second step of the study was to examine the urban-rural effects on the efficiency of schools by determining the efficiency distribution differences of urban and rural schools. Although all schools under observation were assumed to have the same production technology in a nonparametric framework and face the same best-practice DEA frontier, urban and rural schools might practice different production technologies if significant differences between urban and rural schools exist. Urban and rural schools may have their own separate best-practice DEA frontiers, since rural Thai schools are less equipped and have fewer well-qualified teachers 
compared to urban ones, and students in cities have access to better-quality schools and more opportunities to continue postsecondary education (Atagi, 2002). To take this possibility into account, the study examined the frontier differences similar to the investigations featured in the works of Brockett and Golany (1996) and Soteriou et al. (1998). Figure 3 illustrates this possibility. Assume that schools C, D, and E are all rural schools and $y_{s} y_{s}$ represents its own separate frontier. Schools A and B are both urban schools, with the pooled frontier $y_{p} y_{p}$. In this case, the technical efficiency of school $E$ equals $[1 /(\mathrm{OE} / \mathrm{OE} ?)]$ and $[1 /(\mathrm{OE} / \mathrm{OE} ? ?)]$ when measured relative to the separate and pooled frontiers, respectively. The difference between the separate and pooled frontiers is the distance between the two frontiers OE? ? OE? This relative distance thus equals the ratio of the efficiency of school $\mathrm{E}$ relative to the pooled frontier to the separate frontier, [1/(OE/ OE??)] / [1/(OE/ OE?)]. The ratio captures the difference in the frontiers of urban and rural schools and approaches unity as the difference between the two frontiers diminishes.

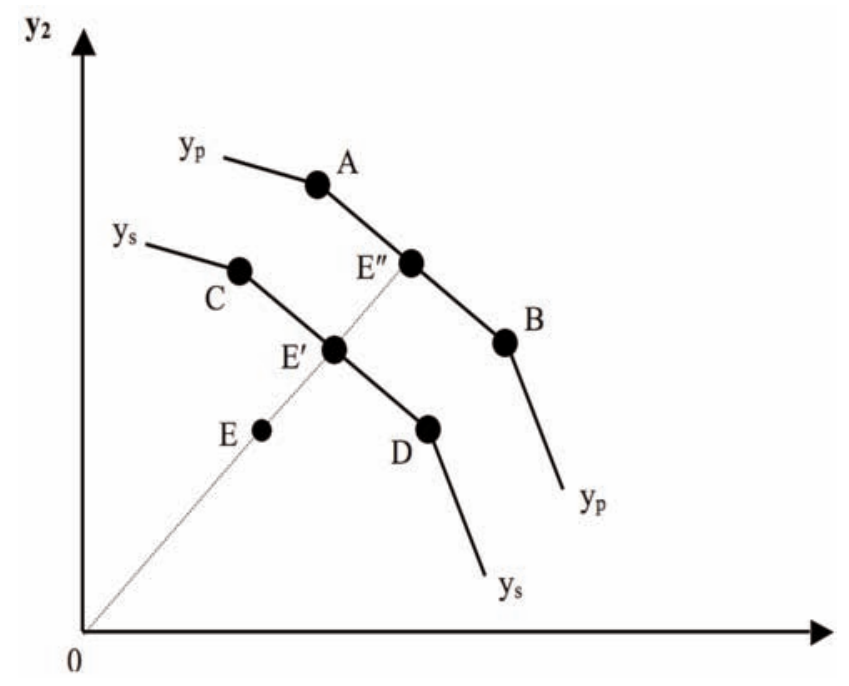

Figure 3. Separate and Pooled Frontiers

The third step of the study was to examine the robustness of urban-rural effects on efficiency. To ascertain the robustness, two other input and output specifications were adopted to examine whether additional modifications in the educational production function could result in substantive changes in the empirical findings of urban-rural effects on efficiency. In addition to primal specification (Specification 1), one output variable was divided into three subvariables in Specification 2. In Specification 3, one input variable was added.
Consequently, the study could explore the estimations of the Mann-Whitney nonparametric rank test for all specifications for the robustness of the effects on efficiency.

\section{Data and Results}

Data came from the Ministry of Education (MOE), Student Loans Fund, National Statistical Office (NSO), and the schools themselves (455 public general uppersecondary schools in northern Thailand in 2003). Due to the unbalanced infrastructure development among regions in the country (Kittiprapas, 1999), the study used a sample only one region because about 32 percent of northern area's schools are in urban areas-the same proportion as the urban population of the country (UNDP, 2005). Thus, about two-thirds of the northern region is rural, with low-income and low-SES school populations and fewer educational resources than their urban counterparts (ONEC, 2001).

All of these schools in the sample were under the same regulations of the Office of the Basic Education Commission (OBEC) of the MOE and used the same curriculum, thus ensuring homogeneity across the schools and the same production technology across the schools, following the DEA constraint. The sample consisted of 149 urban schools and 306 rural schools, defining "urban" as being within municipal areas and "rural" as being outside such areas-Thailand has no classification of "urban" or "rural" as such (Prachuabmoh, Knodel, Prasithrathsin, \& Debavalya, 1972). All municipal areas have some characteristics generally recognized as being urban, while nonmunicipal (rural) areas are nonurban; this classification method is basically used by Thailand's National Statistical Office (NSO).

Evaluators of school efficiency had to consider not only controllable input variables, which are the educational resources available to students, but also uncontrollable inputs, which reflect students' different backgrounds such as socioeconomic and family status, and outputs that reflect academic quantity and quality of the students (Bradley et al., 2001; Chalos \& Cherian, 1995; Kantabutra \& Tang, 2006; Mancebón \& Bandrés, 1999; Mante \& O'Brien, 2002).

Inputs $\left(X_{\mathrm{i}}\right)$ used in this study were teacher-student ratio (Kantabutra \& Tang, 2006; Kantabutra, 2008; Mancebón \& Bandrés, 1999; Mante \& O’Brien, 2002) and proportion of students not from low-income families (Bradley et al., 2001; Chalos \& Cherian, 1995; Kantabutra \& Tang, 2006; Kantabutra, 2008), to reflect the quantity of resources available (e.g., teachers) and 
quality of inputs (e.g., students). Because general uppersecondary school lasts for three years, the study's input data covers 2001-2003, measured as an average whenever possible.

To measure school outputs $\left(y_{r}\right)$, average national test scores (Kantabutra \& Tang, 2006; Kantabutra, 2008; Kirjavainen \& Loikkanen, 1998; Mancebón \& Bandrés, 1999; Mante \& O'Brien, 2002), the number of students who passed their grades after first and second year (average of 2001-02) or were moved up (Kantabutra \& Tang, 2006; Kantabutra, 2008; Kirjavainen \& Loikkanen, 1998), and the number of graduates (Kantabutra \& Tang, 2006; Kantabutra, 2008; Kirjavainen \& Loikkanen, 1998) were included. The average national test score (SAT) is the comprehensive, standardized national achievement test required of all 12th grade students. It tests the extent to which the students' learning experience has developed their verbal, numerical, and analytical abilities. This study includes both qualitative and quantitative output variables since for a given set of inputs, some best-practice schools may produce a small number of high-quality graduates, whereas others may produce high quantities of students of low quality. (A full list of descriptive statistics of input and output variables, together with description of variables, is provided in the Appendix.)

The study carried out three technical efficiency measures for each school, using the output maximization linear programming [Equation (1)], measurement when the sample was partitioned (Separate), measurement for the sample as a whole (Pooled), and a comparison of separate and pooled efficiency measures (Separate/Pooled). Results are shown in Table 1. Efficiency measures indicate the degree to which output could be proportionally increased using the same number of inputs. For instance, an efficiency score of 1.80 implies that outputs of the school in question could be expanded by 0.80 , or 80 percent, $(1.80-1)$ without consuming additional input.

To benchmark urban-rural effects on school efficiency, comparing the mean values shown in Table 1 for the Separate/Pooled measures of urban and rural schoolsvalues of (0.8014) and (0.9552), respectively_-suggests that urban and rural schools may have different frontiers. This may be because, at any level of outputs, urban schools may practice more sophisticated production technology by using advanced educational tools or more professional teachers. The frontier difference was assessed by using a nonparametric Mann-Whitney rank statistical test.
The null hypothesis (a,b) is that, for urban schools (a) and rural schools (b), there is no difference between the distributions of their separate and their pooled efficiency measures. The results in Table 2 indicate that at the 99 percent level of confidence, null hypothesis (a) is rejected, whereas null hypothesis (b) cannot be rejected. The findings suggest that the urban schools have their own frontier, which is different from that of the pool, while the separate and pooled frontiers of rural schools are not distinguishable. One likely explanation is that urban
Table 1. Efficiency Results

\begin{tabular}{|l|c|c|}
\hline Efficiency Measure & Urban Schools & Rural Schools \\
\hline Separate & Mean (S.D.) & Mean (S.D.) \\
\hline Pooled & $1.5855(0.4308)$ & $2.2726(0.7527)$ \\
\hline Separate/Pooled & $2.0593(0.7397)$ & $2.3605(0.7168)$ \\
\hline
\end{tabular}

institutions may have access to and practice different production technologies than do institutions in the countryside.

Mean values of separate efficiency scores (Separate) of urban schools (Table 1) are higher than those in the rural schools, suggesting that urban schools may be clos-
Table 2. Mann-Whitney Test Results

\begin{tabular}{|l|c|}
\hline \multicolumn{1}{|c|}{ Schools } & U Statistic (P-value) \\
\hline Urban (separate vs. pooled) & $6420(0.0000)^{* *}$ \\
\hline Rural (separate vs. pooled) & $43541(0.1341)$ \\
\hline Pooled (urban vs. rural) & $16780(0.0000)^{* *}$ \\
\hline $\begin{array}{l}\text { a Null hypothesis: For urban schools, there is no difference between } \\
\text { the distributions of their separate efficiency measures and their } \\
\text { pooled efficiency measures. } \\
\text { b Null hypothesis: For rural schools, there is no difference between } \\
\text { the distributions of their separate efficiency measures and their } \\
\text { pooled efficiency measures. } \\
\text { c Null hypothesis: There is no difference between the efficiency distri- } \\
\text { butions of urban and rural schools when the sample is pooled. } \\
* * \text { Significant at the } 1 \% \text { level }\end{array}$ \\
\hline
\end{tabular}

er on average to their separate frontier when compared with their rural counterparts. When the two groups are judged in the pooled sample, the average level of efficiency measures for urban and rural schools (Pooled) are 2.0593 and 2.3605, respectively. The higher average efficiency of urban schools suggests that they may perform 
more efficiently than rural ones when both are judged relative to the pooled frontier. Moreover, these figures indicate that for existing input levels, on average, both groups of schools are producing too few outputs: the shortfall for urban institutions is 51.44 percent and, for rural ones, 57.64 percent (i.e., 1-1/2.0593 and 1$1 / 2.3605$, respectively).

The study further assessed the difference in average efficiency between urban and rural schools by the difference in efficiency distributions of these two groups when the sample was pooled. The null hypothesis (c) is that there is no difference between the efficiency distributions of the two groupings when the sample is pooled. Table 2 summarizes the results. The null hypothesis was rejected at the 99 percent level of confidence, indicating that the efficiency distributions of the two types of institutions are different for the pooled efficiency measures: in the sample, rural schools appear to be less productive than urban ones. These findings are consistent with the research of Adewuyi (2002) and Mancebón and Bandrés (1999).

The study conducted sensitivity analysis to ascertain the robustness of the analytical framework and resulting measures of urban-rural effects on efficiency. Two other specifications were defined to determine whether minor specification changes would considerably change the results from the primal specification. All three model specifications are provided in the Appendix. For the first additional specification (specification 2), the output, national test scores (SAT), was divided into verbal, numerical, and analytical ability scores from specification 1. In specification 3, teaching aide-student ratio was included as an alternative school input in addition to specification 2. Efficiency scores of schools in the sample were calculated using the output-oriented DEA model (Equation 1) together with the two additional specifications of the schools' production function.

Statistics of efficiency scores of the two alternatives of educational production functions (specifications 2 and 3) are presented in Table 3 (see appendix, page 11) to compare with those of the primal specification (specification 1). The efficiency scores of the two alternatives are consistent with those of the primal specification in two aspects: (1) both urban and rural institutions' scores, when measured against their own separate frontiers, are higher than when gauged against the pooled sample's frontier; this suggests that they may operate closer, on average, to their respective separate frontiers and that both separate frontiers are different from the pooled one; and (2) when both groups' efficiency is judged relative to their own separate and the pooled frontiers, rural schools, on average, have lower efficiency scores compared to those in the city; this suggests that, on average, rural schools may operate less efficiently compared to urban ones.

Consequently, the study examined the robustness of urban-rural effects on all three specifications through Mann-Whitney statistical rank test analysis. Table 4 (see appendix, page 11) summarizes the results. For both alternatives (specifications 2 and 3), the results suggest the robustness for all measures and indicate that the separate and pooled frontiers of rural schools cannot be distinguished from each other, while the distributions of separate and pooled efficiency scores of urban schools are significantly different at the 99 percent level of confidence. When urban and rural schools are judged relative to the pooled frontier, efficiency score distributions of rural places are significantly different from those of urban ones at the 99 percent level of confidence. Also, the findings seem to indicate that rural schools are less efficient, on average, compared to their urban counterparts.

\section{Conclusion and Policy Implications}

This study analyzed the urban-rural effects on school efficiency for public general upper-secondary schools in northern Thailand. The efficiency measures were assessed using the DEA approach, because DEA has been recognized as a practical method for this purpose. DEA uses benchmarking to measure the efficiency of one school relative to others in its group. Such comparisons can assist in identifying efficient and inefficient schools within the group as well as indicating potential adjustment targets for the inefficient institutions. Furthermore, to provide in-depth understanding of efficiency, the study applied a Mann-Whitney rank test model to examine how education efficiency, as measured using DEA, was affected by location (urban vs. rural). Location is of interest in this study because its effects are important for improving educational services in Thailand.

Results reveal that urban and rural schools appear to have access to and practice different production technologies when both are measured as a pool. Results also show that the average rural school appears to be less efficient than its urban counterpart. This rural deficiency may exist because rural schools often have faced funding drawbacks that urban institutions have not; therefore, they often have less advanced educational equipment and fewer laboratories, handicapping teachers in their efforts to promote learning. In addition, the most sought- 
after teachers, support staffs, and potential students often prefer urban locales to the countryside. For the robustness of urban-rural effects using a Mann-Whitney rank statistical test, results suggest that, for all specifications, rural institutions appear to have access to and practice the same educational production technologies, while their urban counterparts appear to have access to and practice different production technologies. Rural schools are also less productive, on average, compared to urban ones. Therefore, sensitivity analysis suggests that the analytical framework and the resulting measures of the study are robust.

This study, if validated, may have wide implications for national education policy in Thailand. The performance-based DEA results indicate that each school group, urban or rural, has both efficient and inefficient schools, and the adjustment targets of inefficient institutions (e.g., SAT scores) indicate the extent to which these schools can improve their performance. If validated by further research, the findings could be used to prioritize institutions for treatment. Because relatively little analysis has been done on how location affects school efficiency, especially in the context of developing countries, empirical testing of the anticipated theoretical results can prove useful for policymakers.

Given the results of urban-rural effects and educational resource constraints, policymakers may consider varying policy to take geographical area differences into account, viewing rural and urban schools as different from each other. In addition, policymakers may need to consider shifting existing resources from urban schools to rural schools-for example, assigning teachers from the more efficient urban institutions to help relatively inefficient rural schools-provided that the increase in overall rural efficiency would be greater than the decrease, if any, in the city. Also, policymakers may consider allocating new teachers to rural locations (new graduates usually prefer urban locales). This seems to be a feasible course of action, since the National Economic and Social Development Plans in Thailand (NESDB, 2002) have been giving priority to sharing of resources to enhance overall educational efficiency and developing supportive linkages between urban and rural schools. In China, for example, encouraging close relationships between country and city flagship or "key point" schools, with the latter perhaps sending some of their better teachers to the country for a period, has contributed to substantial school quality improvements (Lee \& Li, 1995).

This study focused on the urban-rural effects on school efficiency for only three years (2001-2003).
Future research could focus on analyzing effects on efficiency over time and/or across subgroups or regions in a panel data setting. In addition, other dimensions of school performance should be explored. As Hallinger (2003) points out, developing nations in the Asia Pacific region need to develop their own knowledge base on school leadership to enhance performance; therefore, analyzing the relationship between school leadership and school efficiency would be interesting, particularly for rural schools. The result may be a more complete understanding of the urban-rural effects on school efficiency. Finally, this study used inputs and outputs of the educational production function that may not be fully amenable to other types of schools. Future studies might refine the inputs and outputs on the basis of the objectives of each school type.

\section{Acknowledgment}

I would like to thank Assistant Professor Burin Kantabutra for editing and sharing his crucial insights throughout this research work.

\section{References}

Adewuyi, D. A. (2002). Comparison between school effectiveness characteristics and classroom instruction strategies in the United States and Nigeria. Africa Development, 27(1-2), 263-287.

Anderson, D. R., Sweeney, D. J., \& Williams, T. A. (1997). An introduction to management science: Quantitative approaches to decision making (8th ed.). St. Paul, MN: West Publishing.

Atagi, R. (2002). The Thailand education reform project: School reform policy, ADB TA 3585-THA, Education Sector Reform, Thailand.

Bingler, S., Diamond, B. M., Hill, B., Hoffman, J. L., Howley, C. B., et al. (2002). Dollars \& sense: The cost effectiveness of small schools. Cincinnati, $\mathrm{OH}$ : KnowledgeWorks Foundation.

Booth, A. (1999). Education and economic development in Southeast Asia: Myths and realities. ASEAN Economic Bulletin, 16(3), 290-306.

Bradley, S., Johnes, G., \& Millington, J. (2001). The effect of competition on the efficiency of secondary schools in England. European Journal of Operational Research, 135(3), 545-568.

Brockett, P. L., \& Golany, B. (1996). Using rank statistics for determining programmatic efficiency differ- 
ences in data envelopment analysis. Management Science, 42(3), 466-472.

Chalos, P., \& Cherian, J. (1995). An application of data envelopment analysis to public sector performance measurement and accountability. Journal of Accounting and Public Policy, 14, 143-160.

Charnes, A., Cooper, W. W., \& Rhodes, E. (1978). Measuring the efficiency of decision-making units. European Journal of Operational Research, 2, 429-444.

Cheng, Y. C., \& Townsend, T. (2000). Educational change and development in the Asia Pacific region: Trends and issues. In T. Townsend \& Y. C. Cheng (Eds.), Educational change and development in the Asia Pacific: Challenges for the future (pp. 318-343). Lisse, Netherlands: Swets \& Zeitlinger.

Coelli, T., Rao, D. S. P., \& Battese, G. E. (1998). An Introduction to efficiency and productivity analysis. Boston: Kluwer.

Cooksey, B., Balze, P., \& Burian, B. (1998). Education sector development programme and poverty alleviation strategies. Background paper prepared for the sector development programme, Dar es Salaam: Tanzanian Development Research Group.

de Lancer, P. J. (2000). Decision-making tools for public productivity improvement: A comparison of DEA to cost-benefit and regression analyses. Journal of Public Budgeting, Accounting \& Financial Management, 12(4), 625-646.

Engert, F. (1996). The reporting of school district efficiency: The adequacy of ratio measures. Journal of Public Budgeting, Accounting \& Financial Management, 8(2), 247-271.

Gilbert, A., \& Gugler, J. (1992). Cities, poverty and development: Urbanization in the third world. Oxford, United Kingdom: Oxford University Press.

Hallinger, P. (1998). Educational change in Southeast Asia: The challenge of creating learning systems. Journal of Educational Administration, 36(5), 492-509.

Hallinger, P. (2003). School leadership preparation and development in global perspective. In P. Hallinger (Ed.), Reshaping the landscape of school leadership development: A global perspective (pp. 274-289). Lisse, Netherlands: Swets \& Zeitlinger.

Hanushek, E. A. (1986). The economics of schooling: Production and efficiency in public schools. Journal of Economic Literature, 24, 1141-1177.

Hochschild, J. L. (2003). Social class in public schools. Journal of Social Issues, 59(4), 821-840.
Hugo, G., Griffith, D., Rees, P., Smailes, P., Badcock, B., \& Stimson, R. (1997). Rethinking the ASGC: Some conceptual and practical issues (Monograph Series 3, National Key Centre for Social Applications of GIS). Adelaide, Australia: University of Adelaide.

Jimerson, L. (2006). Breaking the fall: Cushioning the impact of rural declining enrollment. Washington, DC: The Rural School and Community Trust.

Kantabutra, S. (2008). Assessment of size effects on efficiency, In: Innovative Techniques in Instruction Technology, E-learning, E-assessment, and Education: International Conference on Engineering Education, Instructional Technology, Assessment, and E-learning (EIAE 07), Ed. M. Iskander. Springer Netherlands, ISBN: 978-1-40208738-7, 467-472.

Kantabutra, S., \& Kantabutra, S. (2004, September). Investigating relationships between shared vision and public school performance. A proposed model. Paper presented at the International Conference on Making Educational Reform Happen: Learning from the Asian Experience and Comparative Perspectives, Bangkok, Thailand.

Kantabutra, S., \& Kantabutra, S. (2005, November). Heightening public school performance through visionbased leadership: A Thai perspective. Paper presented at the Conference on Quality Educational Leadership: A Partnership of East and West, Bangkok, Thailand.

Kantabutra, S., \& Kantabutra, S. (2006, December). Relating shared vision components to Thai public school performance. Paper presented at the International Conference on Powerful Visions: Do They Work in Asia? (5th Annual Conference of the Asia Academy of Management), Tokyo, Japan.

Kantabutra, S., \& Tang, J. C. S. (2006). Urban-rural and size effects on school efficiency: The case of Northern Thailand. Leadership and Policy in Schools, 5(4), 355-377.

Kirjavainen, T., \& Loikkanen, H. A. (1998). Efficiency differences of Finnish senior secondary schools: An application of DEA and Tobit analysis. Economics of Education Review, 17(4), 377-394.

Kittiprapas, S. (1999). Regional development in Thailand: Divergence and recent deconcentration. Bangkok, Thailand: Thailand Development Research Institute (TDRI).

Knight, J., \& Li, S. (1996). Educational attainment and the rural-urban divide in China. Oxford Bulletin of Economics and Statistics, 58 (1), 83-117. 
Lasley, P., Leistritz, F. L., Lobao, L. M., \& Meyer, K. (1995). Beyond the amber waves of grain: An examination of social and economic restructuring in the Heartland. Boulder, CO: Westview Press.

Lee, W. O., \& Li, Z. (1995). Education, development and regional disparity in Guangzhou. In G. A. Postiglione \& W. O. Lee (Eds.), Social change and educational development: Mainland China, Taiwan and Hong Kong (pp. 46-81). Hong Kong: Centre of Asian Studies, University of Hong Kong.

Manandhar, R., \& Tang, J. C. S. (2002). The evaluation of bank branch performance using data envelopment analysis: A framework. Journal of High Technology Management Research, 13(1), 1-17.

Mancebón, M. J., \& Bandrés, E. (1999). Efficiency evaluation in secondary schools: The key role of model specification and of ex post analysis of results. Education Economics, 7(2), 131-152.

Mante, B., \& O'Brien, G. (2002). Efficiency measurement of Australian public sector organizations: The case of state secondary schools in Victoria. Journal of Educational Administration, 40(3), 274-296.

McColl, A., \& Malhoit, G. (2004). Rural school facilities: State policies that provide students with an environment to promote learning. Washington, DC: Rural School and Community Trust.

Miller, B. A. (1995). The role of rural schools in community development: Policy issues and implications. Journal of Research in Rural Education, 11(3), 163-172.

Morris, J., Bailey, A., Turner, R. K., \& Bateman, I. J. (Eds.) (2001). Managing the environment for sustainable development: Rural planning and management. Cheltenham, United Kingdom: Edward Elgar Publishing.

National Economic and Social Development-NESDB. (2002). Government of Thailand: The Ninth National Economic and Social Development Plan (2002-2006). Bangkok, Thailand: Office of the National Economic and Social Development Board.

Office of Education Council-OEC. (2004). Education in Thailand 2004. Bangkok, Thailand: Amarin Printing and Publishing. Retrieved October 8, 2007, from http://www.edthai.com/publication/edu2004/content.html

Office of the National Education Commission-ONEC. (2001). Education in Thailand 2001/2002. Bangkok, Thailand: Kurusapa Ladprao Publishing. Retrieved
September 20, 2007, from http://www.edthai.com/publication/edu2001/ed_in_ thai.html

Prachuabmoh, V., Knodel, J., Prasithrathsin, S., \& Debavalya, N. (1972). The rural and urban populations of Thailand: Comparative profiles (Institute of Population Studies, Chulalongkorn University, Research Report No. 8). Bangkok, Thailand: Thai Watana Panich Press.

Pritchard, M. (2003). Rural schools: Irreplaceable, unique, endangered. Educational Facility Planner, 39(3), 16-19.

Primont, D. F., \& Domazlicky, B. (2006). Student achievement and efficiency in Missouri Schools and the No Child Left Behind Act. Economics of Education Review, 25(1), 77-90.

Rutter, M., Maughan, B., Mortimore, P., \& Ouston, J. (1979). Fifteen thousand hours: Secondary schools and their effects on children. London: Open Books.

Saitis, C., \& Saiti, A. (2004). School libraries in Greece: A comparative study of public primary schools in rural and urban areas. Library $\&$ Information Science Research, 26(2), 201-220.

Soteriou, A. C., Karahanna, E., Papanastasiou, C., \& Diakourakis, M. S. (1998). Using DEA to evaluate the efficiency of secondary schools: The case of Cyprus. International Journal of Educational Management, 12(2), 65-73.

United Nations Development Programme-UNDP. (2005). Human development report 2005. New York: Oxford University Press.

Watcharasriroj, B., \& Tang, J. C. S. (2004). The effect of size and information technology on hospital efficiency. Journal of High Technology Management Research, 15(1), 1-16.

World Bank. (1996). Thailand: Growth, Poverty, and Income Distribution: An Economic Report. Report No.15689-TH, Washington, D.C.: The World Bank. 


\section{Appendix}

\begin{tabular}{|l|c|c|c|}
\hline \multicolumn{2}{|c|}{ Table 3. Results of Efficiency Scores, Specifications 1-3 } \\
\hline & \multicolumn{3}{|c|}{ Mean (S.D.) } \\
\hline Specification & $1^{*}$ & 2 & 3 \\
\hline Urban Schools & & & \\
\hline Separate & $1.5855(0.4308)$ & $1.4988(0.4026)$ & $1.3915(0.3451)$ \\
\hline Pooled & $2.0593(0.7397)$ & $1.9418(0.6590)$ & $1.8906(0.6578)$ \\
\hline Separate/Pooled & $0.8014(0.1318)$ & $0.7991(0.1320)$ & $0.7674(0.1292)$ \\
\hline Rural Schools & & & \\
\hline Separate & $2.2726(0.7527)$ & $2.1125(0.6810)$ & $2.0359(0.6759)$ \\
\hline Pooled & $2.3605(0.7168)$ & $2.1796(0.6548)$ & $2.1010(0.6535)$ \\
\hline Separate/Pooled & $0.9552(0.0654)$ & $0.9365(0.0583)$ & $0.9640(0.0557)$ \\
\hline * Primal specification & & & \\
\hline
\end{tabular}

\begin{tabular}{|l|c|c|c|}
\hline \multicolumn{4}{|c|}{ Table 4. Mann-Whitney Test Results, Specifications l-3 } \\
\hline & $1^{*}$ & 2 & 3 \\
\hline Specifications & $6420(0.0000)^{* *}$ & $6140(0.0000)^{* *}$ & $5451.5(0.0000)^{* *}$ \\
\hline Urban schools a & & \\
\hline (Separate vs. Pooled) & & $43964(0.1961)$ & $43962(0.1917)$ \\
\hline Rural schools b & $43541(0.1341)$ & & \\
\hline (Separate vs. Pooled) & & $17540(0.0000)^{* *}$ & $18040(0.0003)^{* *}$ \\
\hline Pooled schools c & $16780(0.0000)^{* *}$ & & \\
\hline (Urban vs. Rural) & & & \\
\hline$*$ Primal specification & & & \\
\hline
\end{tabular}




\begin{tabular}{|c|c|c|c|}
\hline Variables & Mean (S.D.) & Min. & Max. \\
\hline \multicolumn{4}{|l|}{ Urban Schools $(n=149)$} \\
\hline \multicolumn{4}{|l|}{ Inputs } \\
\hline Teacher-student ratio (\%) & $4.61(1.2136)$ & 2.66 & 11.35 \\
\hline Proportion of students not from low-income families & $0.60(0.1929)$ & 0.15 & 0.97 \\
\hline Teaching aide-student ratio (\%) & $0.55(0.2118)$ & 0.13 & 1.51 \\
\hline \multicolumn{4}{|l|}{ Outputs } \\
\hline Passing & $608.18(494.0784)$ & 57.00 & $2,389.00$ \\
\hline Graduates & $186.95(158.9557)$ & 19.00 & 779.00 \\
\hline National test score (SAT) & $37.85(6.1910)$ & 28.03 & 60.82 \\
\hline SAT - Verbal Ability & $13.93(1.8318)$ & 10.38 & 22.43 \\
\hline SAT - Numerical Ability & $12.94(2.4161)$ & 9.42 & 22.46 \\
\hline SAT - Analytical Ability & $10.97(2.1574)$ & 7.61 & 18.82 \\
\hline \multicolumn{4}{|l|}{ Rural Schools $(n=306)$} \\
\hline \multicolumn{4}{|l|}{ Inputs } \\
\hline Teacher-student ratio (\%) & $4.85(1.4688)$ & 1.73 & 10.62 \\
\hline Proportion of students not from low-income families & $0.48(0.1853)$ & 0.01 & 0.90 \\
\hline Teaching aide-student ratio (\%) & $0.63(0.3084)$ & 0.00 & 1.94 \\
\hline \multicolumn{4}{|l|}{ Outputs } \\
\hline Passing & $271.93(246.6660)$ & 9.00 & $1,397.00$ \\
\hline Graduates & $80.27(73.5541)$ & 2.00 & 424.00 \\
\hline National test score (SAT) & $35.11(4.9444)$ & 25.44 & 67.82 \\
\hline SAT - Verbal Ability & $13.04(1.5259)$ & 9.73 & 23.08 \\
\hline SAT - Numerical Ability & $11.90(2.1066)$ & 8.00 & 26.00 \\
\hline SAT - Analytical Ability & $10.17(1.8894)$ & 6.77 & 21.51 \\
\hline
\end{tabular}




\begin{tabular}{|c|c|c|c|}
\hline \multicolumn{4}{|l|}{ Table 6. Model Specifications } \\
\hline \multirow[t]{2}{*}{ Variables } & \multicolumn{3}{|c|}{ Specification } \\
\hline & $1^{*}$ & 2 & 3 \\
\hline \multicolumn{4}{|l|}{ Inputs } \\
\hline Teacher-student ratio & $\mathrm{X}$ & $\mathrm{X}$ & $\mathrm{X}$ \\
\hline $\begin{array}{l}\text { Proportion of students not from low-income } \\
\text { families }\end{array}$ & $\mathrm{X}$ & $\mathrm{X}$ & $\mathrm{X}$ \\
\hline Teaching aide-student ratio & & & $\mathrm{X}$ \\
\hline \multicolumn{4}{|l|}{ Outputs } \\
\hline Passing & $\mathrm{X}$ & $\mathrm{X}$ & $\mathrm{X}$ \\
\hline Graduates & $\mathrm{X}$ & $\mathrm{X}$ & $\mathrm{X}$ \\
\hline National test score (SAT) & $\mathrm{X}$ & & \\
\hline SAT - Verbal Ability & & $\mathrm{X}$ & $\mathrm{X}$ \\
\hline SAT - Numerical Ability & & $\mathrm{X}$ & $\bar{X}$ \\
\hline SAT - Analytical Ability & & $\mathrm{X}$ & $\mathrm{X}$ \\
\hline
\end{tabular}




\begin{tabular}{|c|l|}
\hline \multicolumn{1}{|c|}{ Table 7. Description of Variables } & \multicolumn{1}{|c|}{ Variable } \\
\hline Inputs & \multicolumn{1}{|c|}{ Description/Explanation } \\
\hline Teacher-student ratio (\%) & $\begin{array}{l}\text { Proportion of full-time equivalent qualified teachers per } 100 \\
\text { students licensed }\end{array}$ \\
\hline $\begin{array}{c}\text { Proportion of students not from low-income } \\
\text { families }\end{array}$ & $\begin{array}{l}\text { Percentage of students not receiving educational loan fund- } \\
\text { ing from the government during the study period }\end{array}$ \\
\hline Teaching aide-student ratio (\%) & $\begin{array}{l}\text { Proportion of non-full-time equivalent qualified licensed } \\
\text { teachers per } 100 \text { students }\end{array}$ \\
\hline Outputs & $\begin{array}{l}\text { Number of students who passed their grade after and sec- } \\
\text { ond year of the three-year period the first }\end{array}$ \\
\hline Passing & Number of graduates after the study period \\
\hline Graduates & $\begin{array}{l}\text { Sum of verbal, numerical, and analytical scores, where } 100 \\
\text { indicates the maximum possible score }\end{array}$ \\
\hline National test score (SAT) & Verbal test score; maximum of 35\% \\
\hline SAT - Verbal ability & Numerical test score; maximum of 35\% \\
\hline SAT - Numerical ability & Analytical test score; maximum of 30\% \\
\hline SAT - Analytical ability & \\
\hline
\end{tabular}

IJEPL is a joint publication of the Association for Supervision and Curriculum Development, the Faculty of Education at Simon Fraser University, and the College of Education and Human Development at George Mason University. By virtue of their appearance in this open access journal, articles are free to use, with proper attribution, in educational and other non-commercial settings 90 days after initial publication. Copyright for articles published in IJEPL is retained by the authors. More information is available on the IJEPL Web site: http://www.ijepl.org 